Supporting Information for

\title{
Glutamate Gated Proton-Coupled Electron Transfer Activity of a $[\mathrm{NiFe}]-H y d r o g e n a s e$
}

\author{
Brandon L. Greene ${ }^{\dagger}$, Gregory E. Vansuch ${ }^{\dagger}$, Chang-Hao Wu ${ }^{\ddagger}$, Michael W. W. Adams ${ }^{\ddagger}$ and R. \\ Brian Dyer $^{\dagger *}$ \\ ${ }^{\dagger}$ Chemistry Department, Emory University, Atlanta, GA 30322, United States \\ ${ }^{\star}$ Department of Biochemistry, University of Georgia, Athens, GA 30602, United States
}


Supplemental Information Table of Contents

Scheme S1. Proposed catalytic mechanism of [NiFe] hydrogenases

Figure S1. Method of construction of MW0505

Figure S2. Proton reduction activity measurements for $\mathrm{E}_{17} \mathrm{Q}$ SHI

Figure S3. $\mathrm{H}_{2}$ oxidation activity measurements for $\mathrm{E}_{17} \mathrm{Q}$ SHI

Table S1. FTIR peak position summary for $\mathrm{E}_{17} \mathrm{Q}$ and WT SHI at $\mathrm{pH} 7.5$ with $4 \% \mathrm{H}_{2}$

Figure S4. Full CO and CN FTIR spectrum of $\mathrm{E}_{17} \mathrm{Q}$ and WT SHI

Figure S5. Second derivative FTIR spectra of $\mathrm{E}_{17} \mathrm{Q}$ and WT SHI

Figure S6. $\mathrm{pH}$ dependent FTIR and UV-Vis spectra of $\mathrm{E}_{17} \mathrm{Q}$ SHI

Figure S7. Reproduction of WT transient infrared spectrum at $\mathrm{pH} 7.5$

Figure S8. $\mathrm{pH}$ dependent transient IR spectra of $\mathrm{E}_{17} \mathrm{Q}$ between 100-500 ns

Figure S9. $\mathrm{pH}$ dependent transient IR spectra of $\mathrm{E}_{17} \mathrm{Q}$ between 5-10 $\mu \mathrm{s}$

Figure $\mathbf{S 1 0}$. $\mathrm{Ni}_{\mathrm{a}}-\mathrm{S}$ sensitive single wavelength IR kinetics for $\mathrm{E}_{17} \mathrm{Q}$ SHI

Figure S11. Arrhenius plots for hydride recovery at $\mathrm{pH} 6.5$ and 8.5

Supplementary Discussion. Marcus analysis of $\mathrm{E} \rightarrow \mathrm{Q}$ effect on ET rate constant 


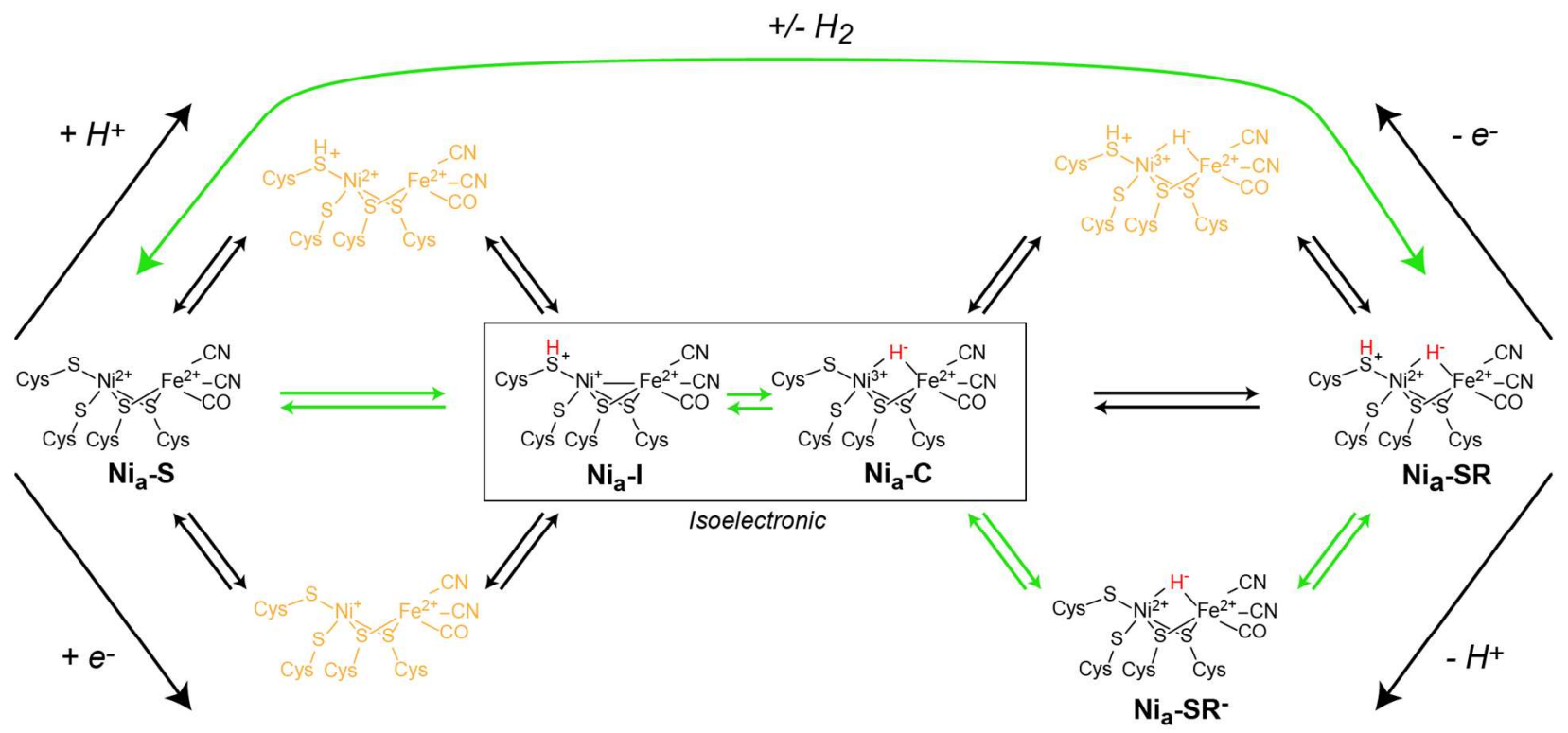

Scheme S1. Enzymatic mechanism of [NiFe] $\mathrm{H}_{2}$ ases. The established catalytic reaction cycle is designated by green arrows, whereas alternative (hypothetical, unproven or disproven) reaction pathways indicated in black. Orange species are proposed to not be involved in the catalytic mechanism. $\mathrm{H}_{2}$ forming protons species are highlighted in red. 


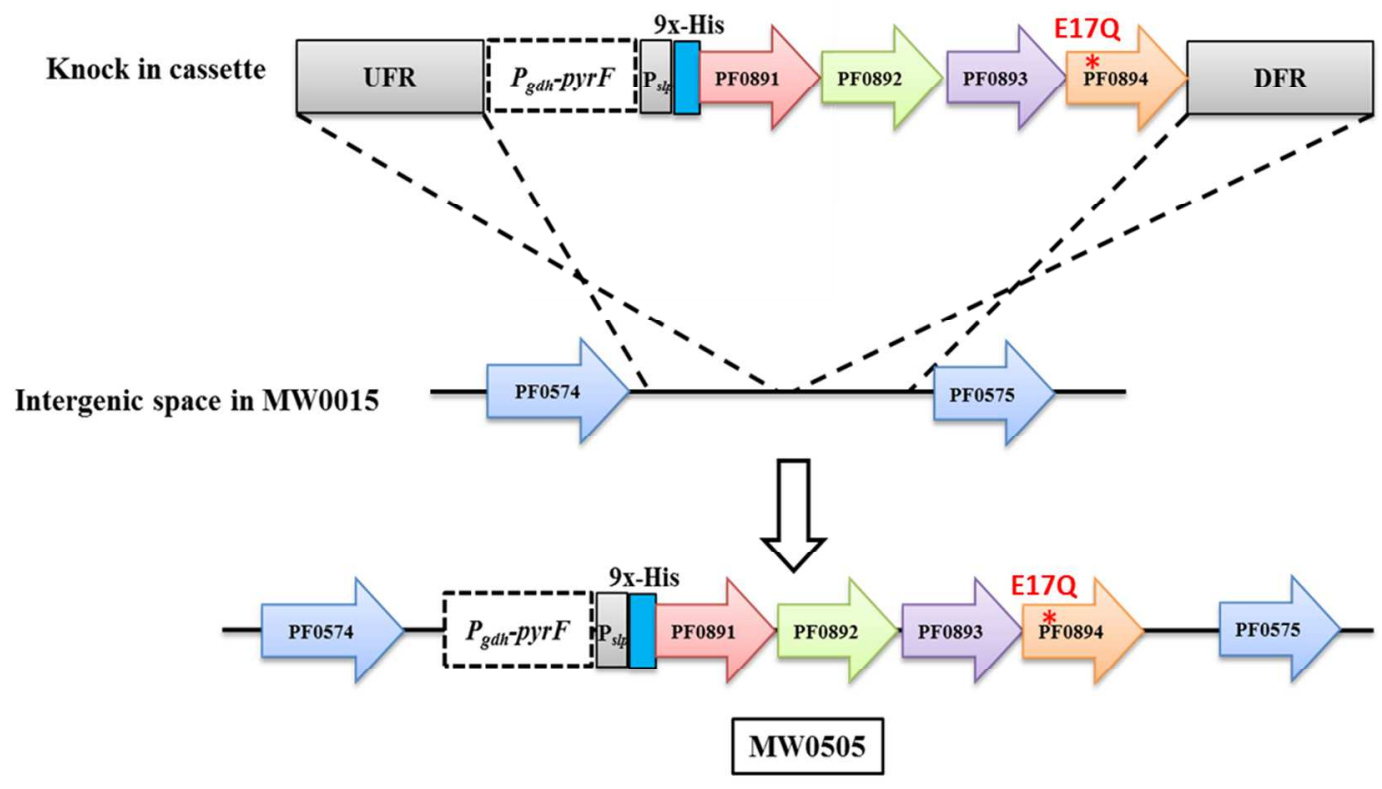

Figure S1. Method of construction of MW0505. The cloning strategy is described in more detail in the Methods section. 


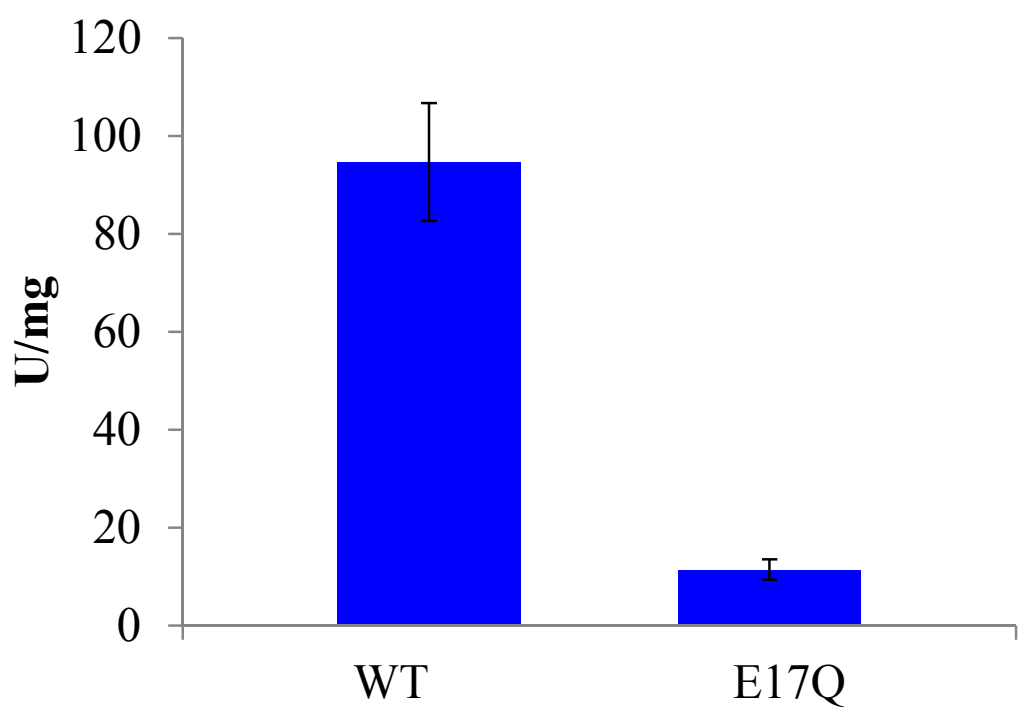

Figure S2. $\mathrm{H}^{+}$reduction activity of $\mathrm{WT}$ and $\mathrm{E}_{17} \mathrm{Q}$ Pf $\mathrm{SHI}$ as measured by $\mathrm{GC}$ of $\mathrm{H}_{2}$ formed in the headspace (see Materials and Methods). 


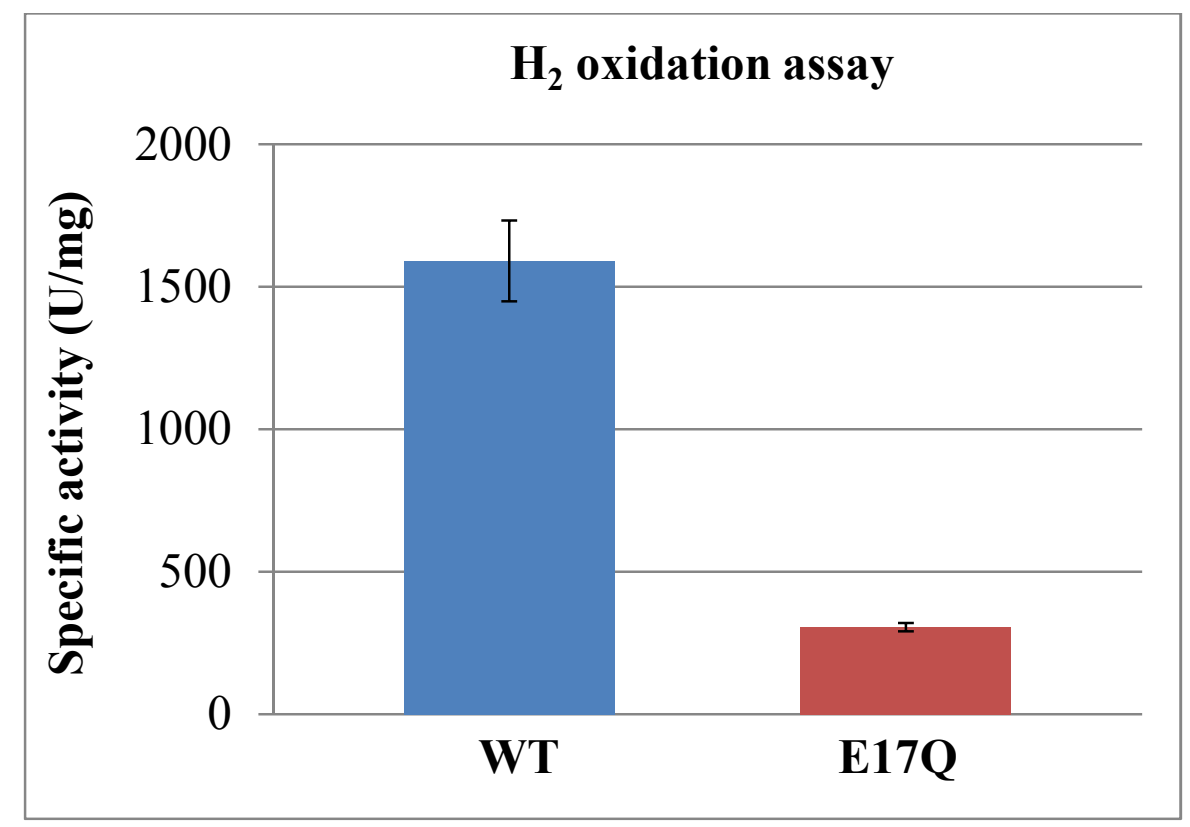

Figure S3. $\mathrm{H}_{2}$ oxidation activity of WT (blue) and $\mathrm{E}_{17} \mathrm{Q}$ Pf SHI. Activities were measured by benzyl viologen reduction at $80^{\circ} \mathrm{C}$ as described in the methods section. WT activity observed at $1600+/-200 \mathrm{U}$ and $\mathrm{E}_{17} \mathrm{Q}$ at $310+/-20 \mathrm{U}\left(19 \%\right.$ WT activity). Activity measured at $21^{\circ} \mathrm{C}$ for E17Q was 26\% WT activity. 
Table S1. Peak position summary for $v_{\mathrm{CO}}$ of $\mathrm{WT}$ and $\mathrm{E}_{17} \mathrm{Q}$ Pf $\mathrm{SHI}$ at $\mathrm{pH} 7.5$ in a $4 \% \mathrm{H}_{2}$ in $\mathrm{N}_{2}$ atmosphere as determined by curve fitting FTIR spectra (see Materials and Methods). n.o. indicates not observed. Values in parenthesis indicate error of the peak fitting, i.e. uncertainty of peak location. Band labeled in red indicates a yet unassigned resonance in the as prepared samples.

\begin{tabular}{ccc} 
State & WT $\left(\mathrm{cm}^{-1}\right)$ & $\mathrm{E}_{17} \mathrm{Q}\left(\mathrm{cm}^{-1}\right)$ \\
\hline $\mathbf{N i}_{\mathbf{a}}-\mathbf{S}$ & $1946.8(5)$ & n.o. \\
$\mathbf{N i}_{\mathbf{a}}-\mathbf{C}$ & $1966.8(1)$ & $1966.2(1)$ \\
$\mathbf{N i}_{\mathbf{a}} \mathbf{- S R}$ & $1952.7(3)$ & $1951.4(1)$ \\
$\mathbf{N i}_{\mathbf{r}}-\mathbf{S}$ & $1931.3(3)$ & 1932.8 \\
$\mathbf{N i - S R}$ & $1939.3(5)$ & $1943.2(1)$ \\
$\mathbf{N i}-\mathbf{X}$ & --- & $1956.6(3)$ \\
\hline
\end{tabular}




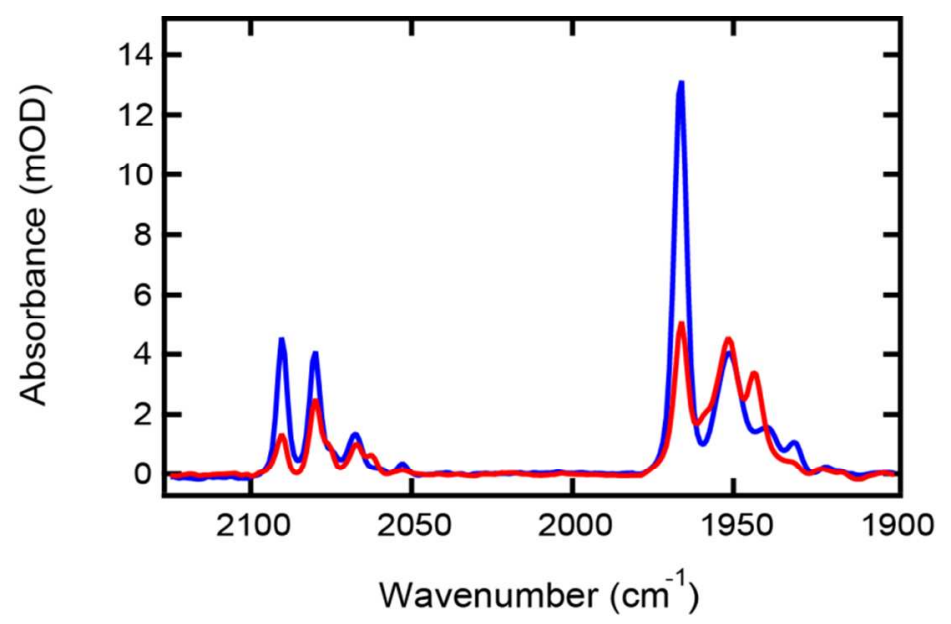

Figure S4. FTIR spectra of WT (blue) and $\mathrm{E}_{17} \mathrm{Q}$ (red) Pf SHI between 2125 and $1900 \mathrm{~cm}^{-1}$. 


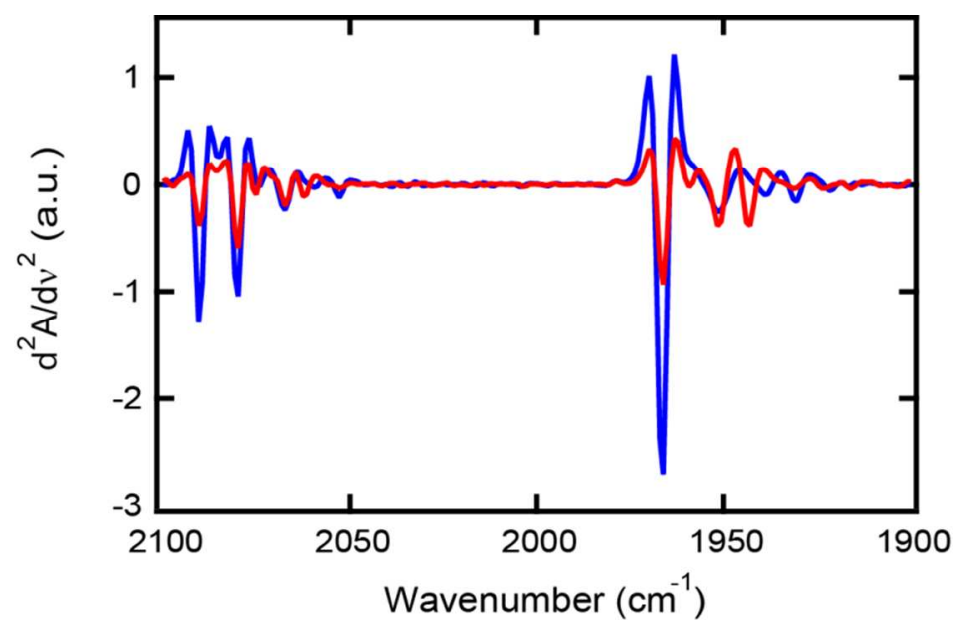

Figure S5. Second derivative FTIR spectra of WT (blue) and $\mathrm{E}_{17} \mathrm{Q}$ (red) Pf SHI derived from spectra reported in Figure S3. 
A

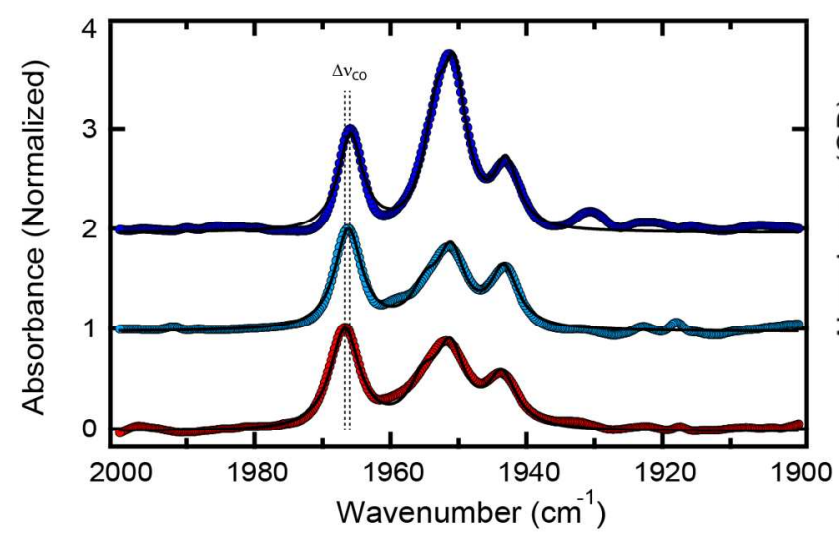

B

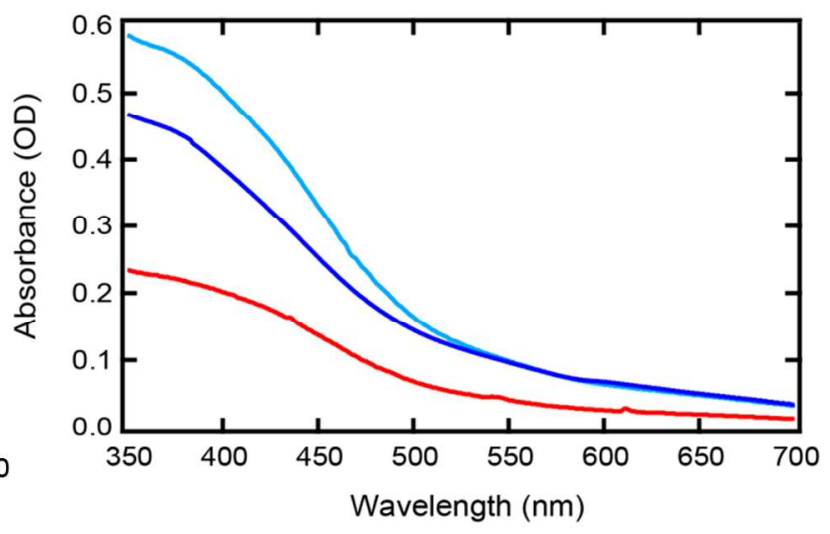

Figure S6. $\mathrm{pH}$ dependent FTIR and UV-Vis of $\mathrm{E}_{17} \mathrm{Q}$ Pf SHI. (A) FTIR spectra of $\mathrm{E}_{17} \mathrm{Q}$ at $\mathrm{pH} 6.5$ (red), 7.5 (light blue) and 8.5 (blue) normalized to the peak $\mathrm{Ni}_{\mathrm{a}}-\mathrm{C}$ absorbance and associated four component Voigt functions (black lines). The $\mathrm{pH}$ dependent shift of the $\mathrm{Ni}_{\mathrm{a}}-\mathrm{C}$ is indicated by dashed lines. (B) UV-Vis spectra of FTIR samples at 6.5 (red), 7.5 (light blue) and 8.5 (blue). 
A

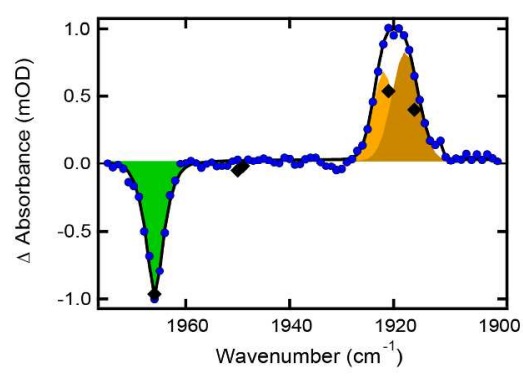

B

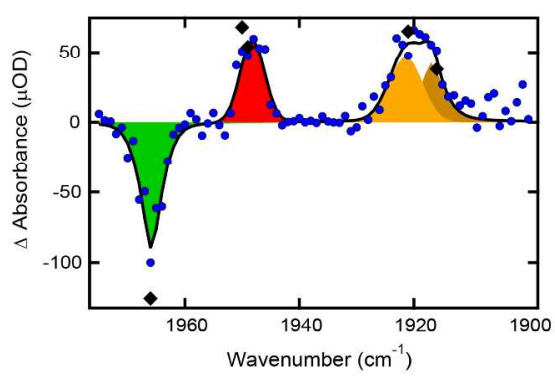

C

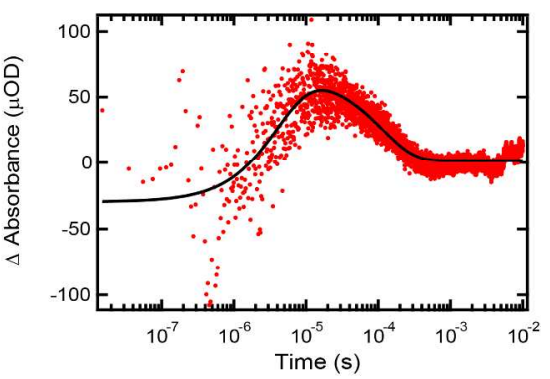

Figure S7. Reproduction of WT transient infrared spectrum at $\mathrm{pH}$ 7.5. Sample prepared at the same time, under identical conditions and measured within 3 hours of the $\mathrm{E}_{17} \mathrm{Q}$ sample reported in the main text. (A) Transient infrared absorbance at 1966, 1950, 1949, 1922 and $1916 \mathrm{~cm}^{-1}$ (black diamonds) overlaid with previously reported $\mathrm{pH} 7.5$ transient spectrum (blue circles) at 100-500 ns. (B) Transient infrared absorbance at 1966, 1950, 1949, 1922 and $1916 \mathrm{~cm}^{-1}$ (black diamonds) overlaid with previously reported $\mathrm{pH} 7.5$ transient spectrum (blue circles) at 5-10 $\mu$ s. (C) Single wavelength transient of $\mathrm{Ni}_{\mathrm{a}}-\mathrm{S}$ recorded at $1949 \mathrm{~cm}^{-1}$ (red circles) and associated double exponential fit. Rate constants $\mathrm{k}_{1}=2.3 \times 10^{5} \mathrm{~s}^{-1}$ and $\mathrm{k}_{2}=8.7 \times 10^{3} \mathrm{~s}^{-1}$. 
A

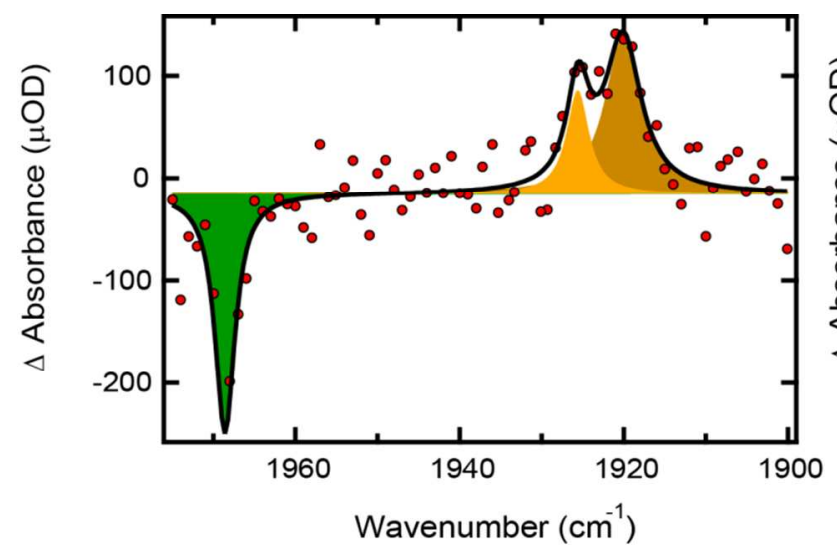

B

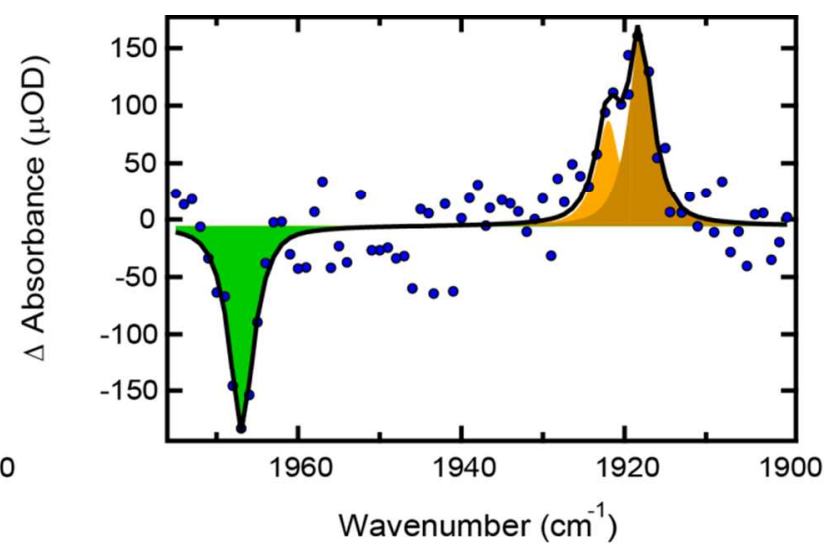

Figure S8. TRIR spectra of $\mathrm{E}_{17} \mathrm{Q}$ SHI between 100-500 ns. (A) TRIR spectrum at pH 6.5 (red dots) and associated three component Voigt fit (black line) and spectral components $\mathrm{Ni}_{\mathrm{a}}-\mathrm{C}$ (green), $\mathrm{Ni}_{\mathrm{a}}-\mathrm{I}^{2}$ (orange) and $\mathrm{Ni}_{\mathrm{a}}-\mathrm{I}^{1}$ (tan). (B) TRIR spectrum at $\mathrm{pH} 8.5$ (blue dots) and associated three component Voigt fit (black line) and spectral components $\mathrm{Ni}_{\mathrm{a}}-\mathrm{C}$ (green), $\mathrm{Ni}_{\mathrm{a}}-\mathrm{I}^{2}$ (orange) and $\mathrm{Ni}_{\mathrm{a}}-\mathrm{I}^{1}(\tan )$. 


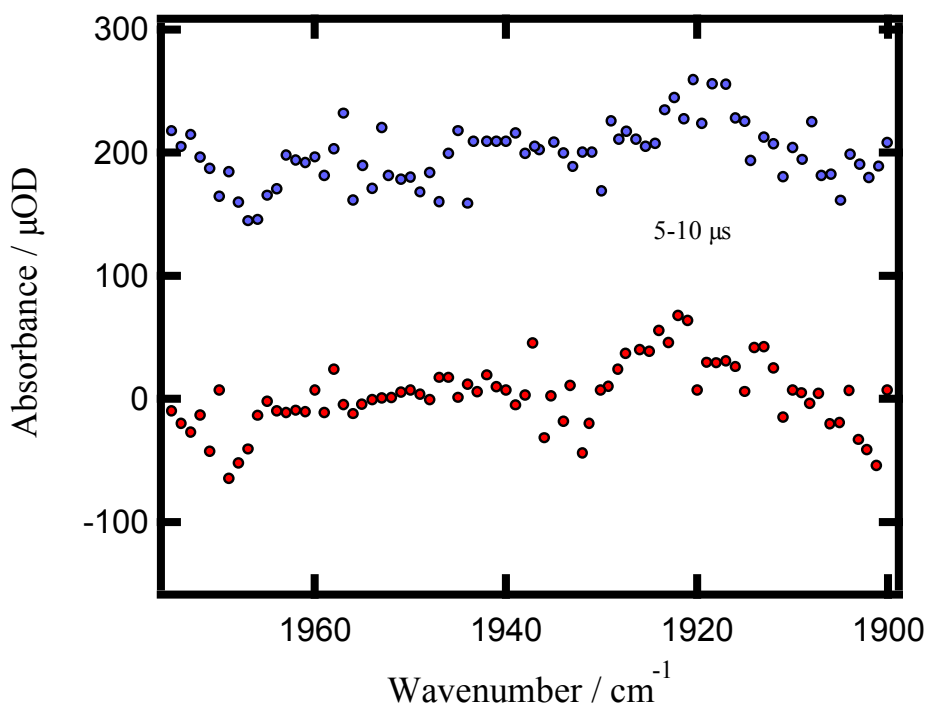

Figure S9. TRIR spectra of $\mathrm{E}_{17} \mathrm{Q}$ SHI between 5-10 $\mu$ s at $\mathrm{pH} 6.5$ (red dots) and $\mathrm{pH} 8.5$ (blue dots); $\mathrm{pH} 8.5$ spectrum is offset for clarity. 


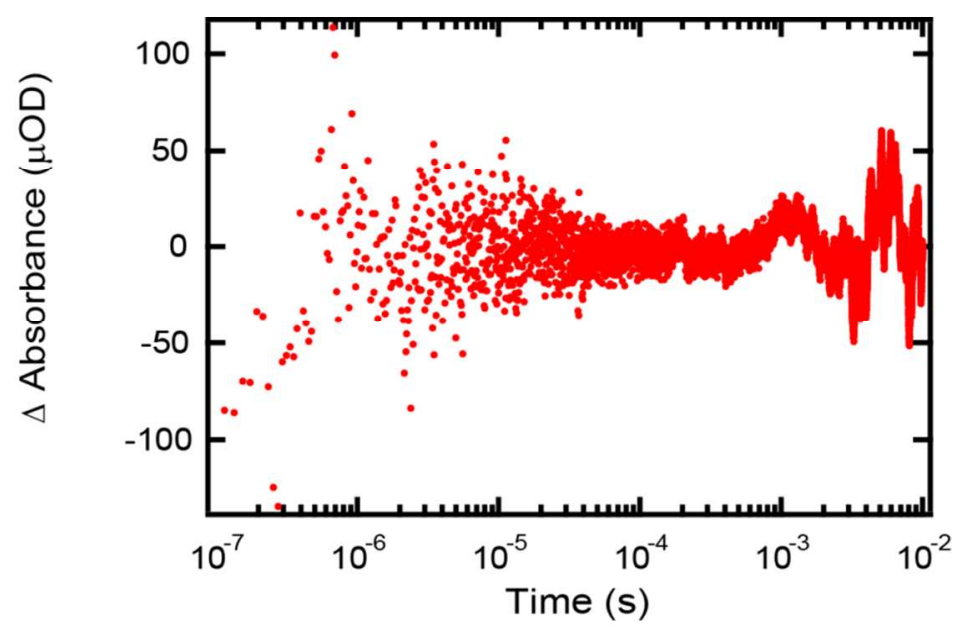

Figure S10. Single wavelength kinetics collected at $1950 \mathrm{~cm}^{-1}$ sensitive to $\mathrm{Ni}_{\mathrm{a}}-\mathrm{S}$ formation. The fluctuations at long time $(>400 \mu \mathrm{s})$ are due to noise of the probe laser. 

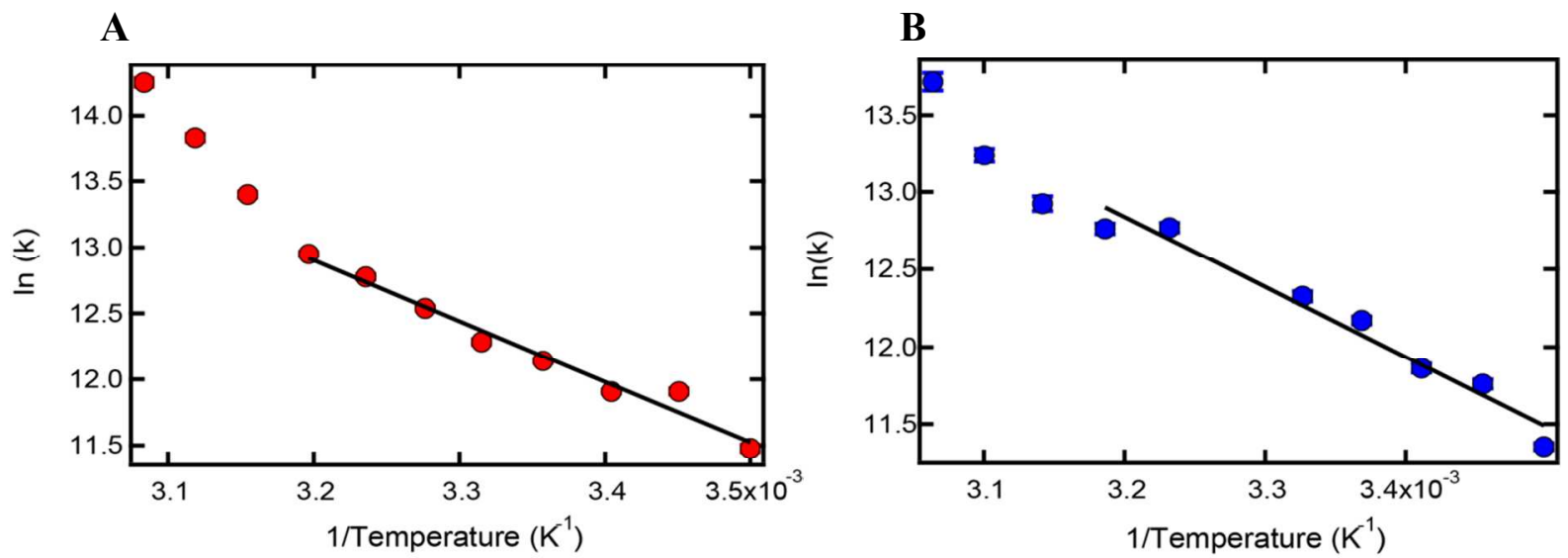

Figure S11. Arrhenius plots for hydride reformation from $\mathrm{Ni}_{\mathrm{a}}-\mathrm{I}^{2}$ of $\mathrm{E}_{17} \mathrm{Q}$ Pf SHI. (A) Arrhenius plot at $\mathrm{pH}$ 6.5. Data fit from 10 to $45^{\circ} \mathrm{C}$ (B) Arrhenius plot at $\mathrm{pH} 8.5$. Data fit from 10 to $45^{\circ} \mathrm{C}$. Previous studies indicate that both steady state proton reduction activity and hydride reformation dynamics follow non-linear relationships above $45^{\circ} \mathrm{C} .{ }^{1-3}$ 
Supplemental Discussion - Marcus analysis of reduction potential perturbation of $E \rightarrow Q$ substitution.

The $\mathrm{E} \rightarrow \mathrm{Q}$ mutation can affect numerous components of PCET in a protein environment. As discussed in the text, the most obvious difference between glutamate and glutamine is the $\mathrm{pK}_{\mathrm{a}}$ of the sidechain, where the carboxylate of glutamate has the potential to become protonated at physiological $\mathrm{pH}$ under certain conditions, but the amide of glutamine cannot. An alternative effect on PCET could be envisioned, where the difference in sidechain electrostatics and Hbonding between $\mathrm{E}$ and $\mathrm{Q}$ may perturb the reduction potential of the active site. Of course the most likely scenario would represent some combination of the two contributions. To estimate the electronic effect on redox properties of the $\mathrm{E}_{17} \mathrm{Q} \mathrm{SHI}$ active site, we consider the kinetic observation that no intensity of $\mathrm{Ni}_{\mathrm{a}}-\mathrm{S}$ is observed over the entire lifetime of the Ni-I ${ }^{1 / 2}$ transient species. Based on the experimental signal to noise and the relative lifetimes of $\mathrm{Ni}_{\mathrm{a}}-\mathrm{S}$ and $\mathrm{Ni}_{\mathrm{a}}-\mathrm{I}^{1 / 2}$, we anticipate that a rate retardation of $\sim 10$ would be necessary to account for the lack of observation of transient $\mathrm{Ni}_{\mathrm{a}}-\mathrm{S}$ formation. The kinetics of electron transfer are well described by the Marcus theory of electron transfer described in equation (1)

$$
k_{E T}=\frac{2 \cdot \pi}{\hbar} \cdot\left|H_{A B}\right|^{2} \cdot \frac{1}{\sqrt{4 \cdot \pi \cdot \lambda \cdot k_{B} \cdot T}} \cdot e^{-\frac{\left(\lambda+\Delta G^{0}\right)^{2}}{4 \cdot \lambda \cdot k_{B} \cdot T}}
$$

where $\mathrm{k}_{\mathrm{ET}}$ is the rate of electron transfer, $\mathrm{H}_{\mathrm{AB}}$ is the electronic coupling between the donoracceptor pair (iron-sulfur cluster and [NiFe] active site), $\lambda$ is the reorganization energy and $\Delta \mathrm{G}^{0}$ is the Gibbs free energy of the reaction. Given that,

$$
k_{E T}^{W T} \geq 10 \cdot k_{E T}^{E 17 Q}
$$

and assuming that the electronic coupling and the reorganization energy are not affected by the $\mathrm{E} \rightarrow \mathrm{Q}$ substitution, one can conclude that

$$
\frac{k^{W T}}{k^{E 17 Q}}=\frac{e^{-\frac{\left(\lambda+\Delta G_{W T}^{0}\right)^{2}}{4 \cdot \lambda \cdot k_{B} \cdot T}}}{e^{-\frac{\left(\lambda+\Delta G_{E 17 Q}^{0}\right)^{2}}{4 \cdot \lambda \cdot k_{B} \cdot T}}} \geq 10
$$

Given this relationship, we can solve for $\Delta \mathrm{G}_{\mathrm{E} 17 \mathrm{Q}}^{0}$, knowing that $\Delta \mathrm{G}_{\mathrm{WT}}^{0}=-1 \mathrm{~kJ} / \mathrm{mol}$ and assuming a reasonable $\lambda$ of $1 \mathrm{eV}$. Based on this analysis, $\Delta \mathrm{G}_{\mathrm{E} 17 \mathrm{Q}}^{0} \geq 12 \mathrm{~kJ} / \mathrm{mol}$, or $\leq-120 \mathrm{mV}$ change in redox potential of the $\mathrm{Ni}_{\mathrm{a}}-\mathrm{S} / \mathrm{Ni}_{\mathrm{a}}-\mathrm{I}^{1}$ couple. 


\section{References.}

(1) Bryant, F. O.; Adams, M. W. J. Biol. Chem. 1989, 264, 5070-9.

(2) Greene, B. L.; Wu, C. H.; McTernan, P. M.; Adams, M. W.; Dyer, R. B. J. Am. Chem. Soc. 2015, 137, 4558-66.

(3) Greene, B. L.; Wu, C. H.; Vansuch, G. E.; Adams, M. W.; Dyer, R. B. Biochemistry 2016, 55, 1813-25. 